Der gebrauchte Text 


\author{
Stephan Mösch
}

\title{
Der gebrauchte Text
}

Studien zu den Libretti Boris Blachers

Verlag J. B. Metzler Stuttgart · Weimar 
D 83

Die Deutsche Bibliothek - CIP-Einheitsaufnahme

Ein Titeldatensatz für diese Publikation ist bei Der Deutschen Bibliothek erhältlich.

ISBN 978-3-476-45305-1

ISBN 978-3-476-02902-7 (eBook)

DOI 10.1007/978-3-476-02902-7

Dieses Werk einschließlich aller seiner Teile ist urheberrechtlich geschützt. Jede Verwertung außerhalb der engen Grenzen des Urheberrechtsgesetzes ist ohne Zustimmung des Verlages unzulässig und strafbar. Das gilt insbesondere für Vervielfältigungen, Übersetzungen, Mikroverfilmungen und die Einspeicherung und Verarbeitung in elektronischen Systemen.

M \& P Schriftenreihe für Wissenschaft und Forschung

(C) 2002 Springer-Verlag GmbH Deutschland

Ursprünglich erschienen bei J.B.Metzlersche Verlagsbuchhandlung und Carl Ernst Poeschel Verlag GmbH in Stuttgart 2002 
Inhalt

1. Ortsbestimmung. ........................... 1

1.1 Blacher heute? Fragen, Methodik und Ziel der Arbeit ........ 3

1.2 Zum Forschungsstand ........................ 27

2. Voraussetzungen und Vorbehalte: Der Operntext als

Literaturadaption ......................... 33

2.1 Das Libretto zwischen Funktionalität und Autonomie ......... 35

2.2 Literaturoper, die obsolete Innovation ............... 49

3. Mit den Worten: „Dantons Tod“

3.1 Umstände eines Einstandes . . . . . . . . . . . . . . . . . 73

3.2 Intentionen und Positionen ....................... 84

3.3 Intermezzo: Aspekte der Vorlage . . . . . . . . . . . . . . . . . 91

3.4 Zum Textkorpus .......................... 98

3.5 Dichterliebe, Dichterferne: Im Transformationsproze $3 . \ldots \ldots \ldots .101$

3.5.1 Das Motto. . . . . . . . . . . . . . . . . . . . . . . 101

3.5.2 Aufbau ................................... 104

3.5 .3 Bild I . . . . . . . . . . . . . . . . . . . . . 112

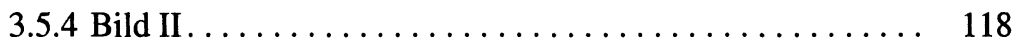

3.5 .5 Bild III . . . . . . . . . . . . . . . . . . . . . . . 128

3.5 .6 Bild IV . . . . . . . . . . . . . . . . . . . 132

3.5.7 Bild V. . . . . . . . . . . . . . . . . . . . . . . . . . . . . 140

3.5 .8 Bild VI . . . . . . . . . . . . . . . . . . . . . 144

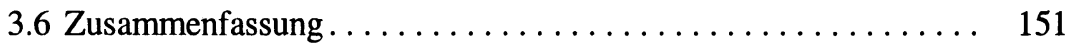

4. Jenseits der Worte: „Abstrakte Oper Nr. 1“.......... 159

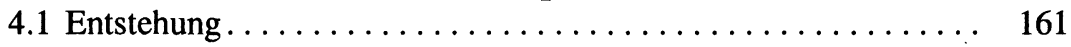

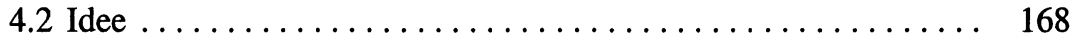

4.3 Struktur . . . . . . . . . . . . . . . . . . . . . . 175

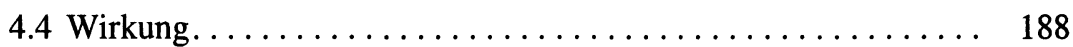

4.5 Zum Dada-Kontext . . . . . . . . . . . . . . . . . . . . . . . . . 193

4.6 Abstraktes, Absurdes, Groteskes: Folgen für das Musiktheater . . 199 
5. Unter den Worten: „Yvonne, Prinzessin von Burgund“... 207

5.1 Entstehung und Wertung .................... 209

5.2 Voraussetzungen von Blachers Gombrowicz-Rezeption ...... 220

5.2.1 Zur Position des Schauspiels .................... 220

5.2.1.1 Faszination der Unbestimmtheit. . . . . . . . . . . . . . 220

5.2.1.2 Künstliche Kunst ..................... 227

5.2.1.3 Vorläufer und Nachzügler: Gombrowicz im Traditionszusammenhang. ....................... 236

5.2.2 Bühnenmusik zu „Die Trauung“ .............. 245

5.2.2.1 Rezeption....................... 245

5.2.2.2 Musikalischer Befund ................... 249

5.3 Zum Transformationsproze $\beta \ldots \ldots \ldots \ldots \ldots \ldots \ldots \ldots . . \ldots \ldots$

5.3.1 „Nach Gombrowicz“: Der Textkorpus............. 258

5.3.2 Lob der Symmetrie: Der Aufbau . . . . . . . . . . . . . 261

5.3.3 Lob der Askese: Zum Klangbild .............. 266

5.3.4 Die sechsfache „Yvonne“: Ein Fassungsvergleich ...... 277

5.3.5 Wie beredt ist das Schweigen? Yvonne als stumme Figur 291

5.4 Zusammenfassung. ........................ 319

6. Statt eines Fazits: „Arbeit am Bewußtsein der Zeit“...... 325

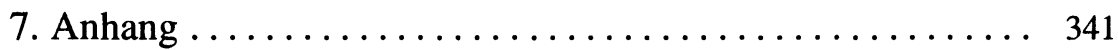

7.1 Zeittafel ................................. 344

7.2 Abkürzungsverzeichnis ...................... 354

7.3 „Yvonne“-Textfassungen ....................... 355

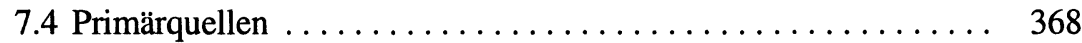

7.5 Selbstzeugnisse von Blacher . . . . . . . . . . . . . . . . 369

7.6 Schriften über Blacher. . . . . . . . . . . . . . . . . . . . . . 370

7.7 Sekundärliteratur....................... 375

7.7.1 Zur Musik- und Librettogeschichte ............. 375

7.7.2 Zur Literatur-, Theater- und Kunstgeschichte ......... 386

7.8 Register ................................ 394

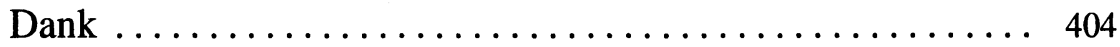

